\title{
Mobile Communication
}

\author{
Sanjita Lamichhane \\ WRC, Institute of Engineering, Lamachour, Pokhara \\ Correspondence:pearl_sanjita@yahoo.com
}

\begin{abstract}
Today's technology is essential tools of the teaching trade. Many using technology young children in particular make effective use of the technology to acquire, create and display the knowledge that they are gaining. Study focuses on how action learning sets help pre-service teachers (PSTS) to use mobile phones for developing pedagogy. These school-based, action-learning group of PSTs allocate five schools are participate in the study. The findings indicated that the m-learning sets provide a vehicle for critical discussion and feedback for their learning and hence support sustain to target professional growth.
\end{abstract}

Keywords: communication, learning, educational technology. radiation hazards.

\section{Introduction}

Teachers who are keen to develop and sustain meaningful connections with their students feel motivated to acquire the necessary technological skills. They argue that professional development programs need to focus not only on the technology, skills and knowledge required to implement learning strategies, but also on the skills and knowledge need to support a blend learning environment that makes appropriate and target use of technologies that support the overall learning goals. Mobile, telephone, television, computer, internet etc are few examples. Among them mobile phone is easy and portable device to carry. So, how mobile communication is helping teaching /learning is seems to be relevant to discuss here.

Mobile communication today is the most powerful device for change in lifestyle of the people all over the world. Mobile communication is evolving as the backbone for business transactions and as a prerequisite for many other forms of communication. The decreasing cost of mobile technologies and telecommunications service provision has revolutionized the take-up of mobile communications technology. Complementary to this rapid proliferation of mobile technologies, we have recently seen the beginning of a convergence of mobile communications and data technologies alongside a variety of newly designed standards, protocols and technologies that allow the more flexible interconnection of handheld information appliances. This goes far beyond supporting simple voice and modem based communications. Whilst data transfers are currently possible, these proposed technologies will support increased levels of flexibility, speed and processing power for data communications. Current approaches to designing mobile information devices follow a model of work that attempts to reproduce tools from the desktop environment onto a small handheld device with limited communications bandwidth.

\section{Historical development}

Ship-to-shore communication was among the first applications of mobile telephony. Experimental service began on coastal steamers between Boston and Baltimore in the US in 1919. The first mobile telephone service started in 1946 in St. Louis, Missouri, US as a manually operated system. Between 1950 and 1960, it evolved as an automatic system with reduced cost but small subscriber base. Mobile telephony service in its useful form appeared in 1960s.First-generation (1G) mobile phones had only voice facility which used analog transmission techniques for the radio link and confined its users to their respective system areas for which the mobile phone was designed. Apart from being very expensive these systems have limited 
capacity. The first generation mobile communication systems appeared in 1970s and remained till 1980s after which these were replaced by second-generation $(2 \mathrm{G})$ digital phones with added fax, data, and messaging services. They supported large subscriber base, voice and limited data services, and uses digital modulation for improved audio quality. It was first used in the early 1990s in Europe. The mobile technology using general packet radio service (GPRS) standard has been termed as $2.5 \mathrm{G}$. It enhances the data capacity of GSM by mitigating some of its limitations. GPRS adds packetswitched capabilities to existing GSM and TDMA networks. The $3 \mathrm{G}$ technology adds multimedia facilities to $2 \mathrm{G}$ phones by allowing video, audio, and graphics application. We can watch streaming video or have video telephony. These phones will have the highest speed of up to 2 Mbps. 4G mobile communications have transmission rates up to $20 \mathrm{Mbps}$ - higher than $3 \mathrm{G}$. The technology is expected to have virtual reality (e.g. videos like avatars and realistic Holograms, and the ability to feel as if you are present at an event even if you are not.)

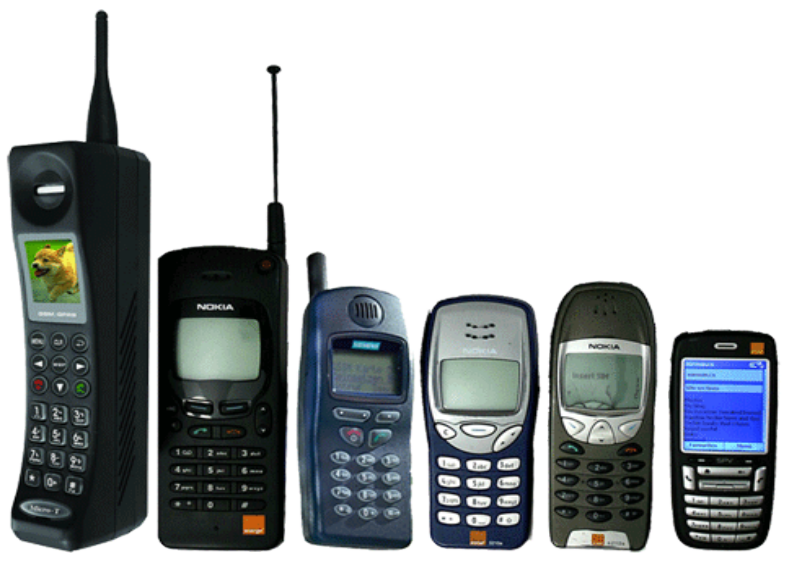

(a) $1 \mathrm{G}$ mobile phones
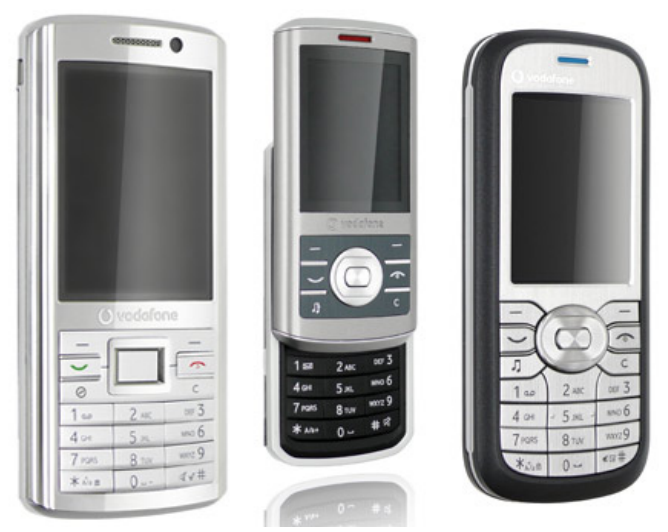

(b) 2G mobile phones

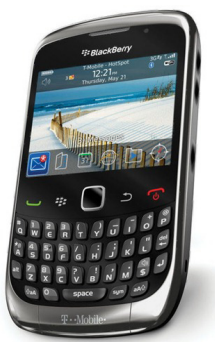

(c) 3G mobile phones

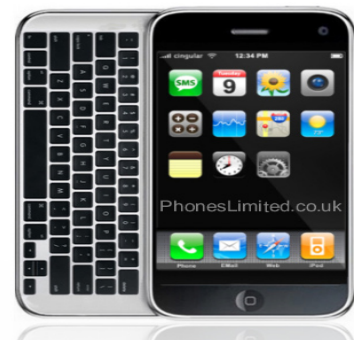

(d) 4G mobile phone
Fig. 1: varieties of mobile sets

\section{Methodology}

Action learning is an effective methodology for many teachers' professional development programs but it needs to be supported by a facilitator whose role is to scaffold practitioner collaborative learning. During this study action learning was used as an educational process where by the participants studied their own actions and experience in order to improve their performance as a teacher. This is done in conjunction with others, in small groups called action learning sets. Each action learning set was located in one of the five participating schools. The 22 preservice teachers involved were divided into action learning sets as follows: four action learning sets each contained four PSTs, and one set contained six PSTs. The participants had access to PalmTreo 680 mobile phones. These devices not only function as a mobile phone, they also have email, messaging, and web access capabilities. In addition they can be used as PDA, as a digital camera (static and video), audio recording and as well as an MP3 device and internet radio. The PalmTreo 680 also supports Word, Excel, PowerPoint and PDF files. The 22 participants (1 male, 21 females) were third year PSTs enrolled in Bachelor. All owned a mobile phone and were very familiar with the basic functions. Three of the 22 participants owned Black Berry mobile phones and were familiar with the advanced features offered by this device.

\section{Results and discussion}

The most successful preservice teacher use of the mobile phones was as a video recording device or as a digital camera. In both cases the preservice teachers were capturing episodes from their lessons that illustrated the impact of their lessons on pupil learning. While 
the audio function was seen as useful when teaching, the difficulty in transferring audio files to a computer limited its use as a follow-up tool for reflection. Some of the other tools such as the cut down Microsoft Office suite of applications were of limited use as the size of the keyboard was seen as a problem for rapid data entry. Instead preservice teachers used standard computers that were available at their schools.

\section{Propagation Phenomenon}

The central concept that made mobile communication as a usable commercial proposition is the cellular Principle. BELL Laboratories, US in 1970 first introduced cellular principle. Under cellular concept, the Service area is divided into a number ofCLUSTERS, each cluster consisting of a number of CELLS and each cell is assigned as many CARRIERS as required by the traffic in that cell (Bennett, Maton \& Kervin, 2008). Each cell is controlled by a base station with a tower which receives and transmits phone signals to mobile users. The wireless link is made up of a twoway path -a forward path (Campbell, 2005) downlink from base station to mobile terminal; a backward path, uplink from mobile terminal to base station. It handles the radio-link protocols with the Mobile Station for call and mobility related activities on one side and with the BSC (Base Station Controller) on the other side. Each BTS (Base Transceiver Station) can support a number of transceivers depending on the capacity of subscribers in the cell. The BTS needs to be rugged, reliable, and portable to ensure reliable service and coverage. Transcoding and Rate adoption Unit (DCDR/TRAU) converts the transmission rate on the land line to that compatible for transmission over the digital radio to and from the MS - Mobile Station (Matthews, 2004). All the base stations are connected by telephone lines to the mobile office switching office (MTSO), which in turn is connected to the telephone central office by phone lines. A caller communicates via radio channel to a cell site base station which sends the signal to MTSO (McCombs \& Liu, 2006). If the called party is the land based, MTSO sends the signal through the central office like any other telephone call. If the called party is mobile, MTSO sends the signal to the base station of the cell where the called party is located. The base station transmits the signal to the called party using the available radio channel in the cell (Miller \& Piller, 2005). As the caller moves from one cell to another, the MTSO automatically switches the user to an available channel in the new cell while the call is in progress.

Each cellular phone has a manufacturer's serial number and the phone number assigned by the phone company. These numbers are automatically transmitted to MTSO during the initialization of the call. The MTSO after authenticating the numbers, assignsto the caller two available frequencies (radio channels), one for transmission and the other for receiving from the base station. When the call terminates, the radio channels become available for another user. The MTSO continuously monitors the signal strength of a phone call, and the signal attenuation beyond some point is viewed as an indication of the caller moving from a previous cell to the next cell.MTSO then searches for a neighbouring cell, where the signal strength from the caller is stronger and then automatically switches the caller to the next base station. The switching is so rapid that it couldn't be noticed. Before cellular communication, a channel could be used only by one user in the city. Because of this, there will be limited number of channels available in a given area. This limitation can be overcome in cellular scheme by reusing the same frequencies (Netsafe, 2005). in all the cells except those immediately adjacent. Since the frequency used being the same, the principle of frequency reuse demands that the interference between them when serving different cells and therefore different customers should be kept within permissible limits. This is possible because the transmitted powers are kept sufficiently small so that the signals from one cell do not propagate beyond the immediately adjacent cells.

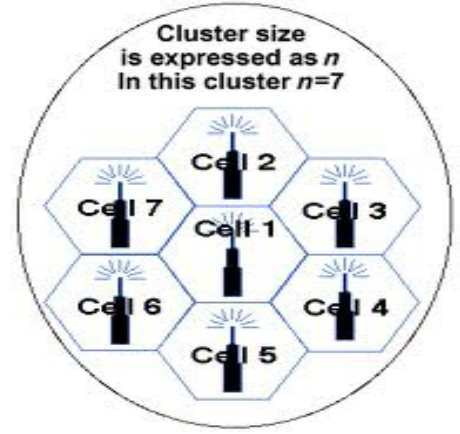




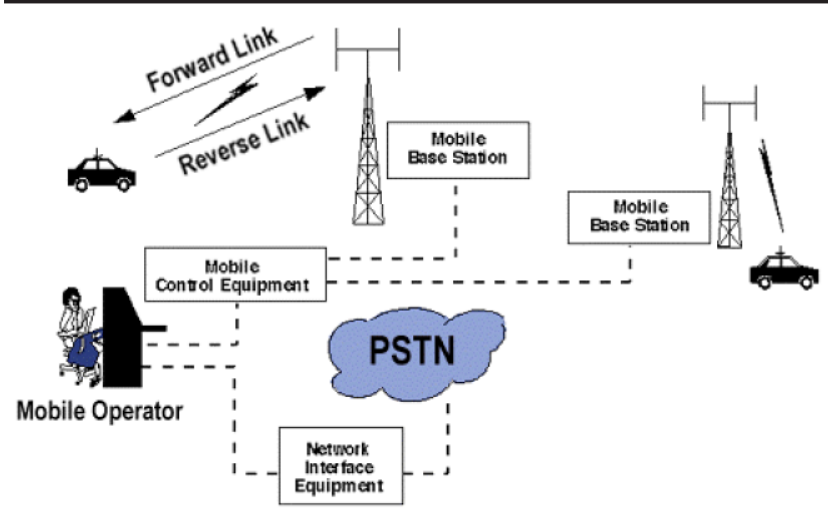

Fig 3: basic mobile telephone service network

The figure above shows a cellular telephone system. The cluster can be repeated any number of times to provide coverage for the service area using the same frequencies. The cluster is repeated in such a manner that the distance between the cells using the same frequency is kept as far as possible. This reuse of frequency will remove the restrictions imposed by the limited bandwidth on the capacity of the system (Sulake, 2008). There are several interference reduction techniques that helps improve the system capacity and performance. The number of RF Channels in each cell is decided on the basis of the traffic load that is expected to be handled in the area served by the cell. It is the cellular concept that enables us to build a network of millions of subscribers.

\section{Conclusion}

An m-learning professional development program should include two aspects - a technology aspect and a pedagogy aspect. The technology aspectneeds to include a basic understanding of telecommunication networks and providers sufficient for participants to know the cost implications of approaches they may adopt, an understanding of the mobile phone functionality and the ability to send, receive and manage messages using an SMS. The pedagogy aspect needs to include some understanding of the mobile phone communication culture of young people, and some understanding of the learning styles of young people. This needs to be supported by a professional learning framework such as action learning in order for teachers to develop the skills and knowledge needed to successfully integrate $\mathrm{m}$-learning strategies into teaching programs. Any form of m-learning needs to be used judiciously and in ways that enhance the work of teachers and their students.

\section{References}

Bennett, S., Maton, K., \& Kervin, L., 2008. The digital natives debate: A critical review of the evidence. British Journal of Educational Technology, 19(5), 775- 786.

Campbell, M. 2005. The impact of the mobile phone on young people's social life. Paper presented to the Social Change in the 21st Century Conference Centre for Social Change Research Queensland University of Technology, 28 Oct 2005.

Matthews, R. 2004. The Pyschoscocial aspects of mobile phone use amongst adolescents. InPsych, 26(6), 16-19.

McCombs, S., \& Liu, Y. 2006. Turning iPod into an effective portable learning tool. In C. Crawford, D. Willis, R. Carlsen, I. Gibson, K. McFerrin, J. Price \& R. Weber (Eds.), Society for information technology and teacher education international conference (pp. 438-443). Chesapeake, VA.AACE.

Miller, M., \& Piller, M. 2005. Principal factors of an audio reading delivery mechanism: Evaluating educational use of the iPod. In P. Kommers \& G. Ricahards (Eds).World Conference on Educational Multimedia, Hypermedia and Telecommunications, (pp.260-267). Chesapeake, VA. AACE.

Netsafe 2005. The text generation: Mobile phones and the Nsew Zealand Youth. A report of result from the Internert Safety Group's survey of teenage mobile phone use. Netsafe: Wellington, NZ.

Sulake 2008. Habbo's second Global Youth Survey reveals the digital profiles of teens online. Available at http://www.sulake.com/press/ releases/20012-04-03 